\title{
The impact of circuit resistance training on serum glucose, insulin resistance and health related physical fitness in elderly men with type 2 diabetes
}

Authors' Contribution: A Study Design B Data Collection C Statistical Analysis D Data Interpretation E Manuscript Preparation F Literature Search G Funds Collection

\author{
Hamid Arazi ${ }^{1}$ ACDEG, Roghayeh Gholizadeh ${ }^{2}$ BCEG, Amin Sohbatzadeh ${ }^{3 \text { BEFG, }}$ \\ Ehsan Eghbali ${ }^{1}$ Def \\ ${ }^{1}$ Department of Exercise Physiology, Faculty of Sport Sciences, \\ University of Guilan, Rasht, Iran. \\ ${ }^{2}$ Department of Exercise Physiology, Faculty of Humanity Sciences, \\ University of Mohaghegh Ardabili, Ardabil, Iran. \\ ${ }^{3}$ Department of Exercise Physiology, Faculty of Sport Sciences, \\ Industrial University of Shahrood, Shahrood, Iran.
}

\section{abstract}

Background: Obesity and decreased physical activity are the most important factors in the development of type 2 diabetes, which in recent decades has led to an increase in the number of people with this disease. The aim of this study was to investigate the impact of circuit resistance training (CRT) on serum glucose, insulin resistance and health related physical fitness in elderly men with type 2 diabetes.

Material and methods: Twenty-two patients with type 2 diabetes ( $60.99 \pm 2.93$ years) volunteered to participate in this study. They were divided randomly into two groups: training $(n=11)$ and control $(n=11)$. Participants in the training group performed a progressive CRT program for ten weeks. In addition, anthropometry variables, muscular strength and endurance were evaluated before and after ten weeks' CRT. Also, $10 \mathrm{ml}$ of the blood sample was taken from participants to measure fasting serum glucose, fasting serum insulin and insulin resistance.

Results: After ten weeks of CRT, the body composition and glucose dropped significantly $(P<0.05)$ in the training group. Also, muscular endurance, upper and lower body strength in the post-test were significantly higher than the pre-test in the training group $(P<0.05)$

Conclusions: CRT led to a significant improvement in insulin resistance, fasting serum glucose, BMI, endurance and strength of elderly men with type 2 diabetes. Therefore, this type of resistance training can be useful for improvement in physical and physiological variables of elderly men with type 2 diabetes.

Key words: circuit resistance training, diabetes, insulin resistance, physical fitness, elderly.

\section{article details}

Article statistics: Word count: 3,061; Tables: 2; Figures: 2; References: 38

Received: October 2019; Accepted: June 2020; Published: September 2020

Full-text PDF: http://www.balticsportscience.com

Copyright @ Gdansk University of Physical Education and Sport, Poland

Indexation: Celdes, Clarivate Analytics Emerging Sources Citation Index (ESCI), CNKI Scholar (China National Knowledge Infrastructure), CNPIEC, De Gruyter - IBR (International Bibliography of Reviews of Scholarly Literature in the Humanities and Social Sciences), De Gruyter - IBZ (International Bibliography of Periodical Literature in the Humanities and Social Sciences), DOAJ, EBSCO - Central \& Eastern European Academic Source, EBSCO - SPORTDiscus, EBSCO Discovery Service, Google Scholar, Index Copernicus, J-Gate, Naviga (Softweco, Primo Central (ExLibris), ProQuest - Family Health, ProQuest - Health \& Medical Complete, ProQuest - Illustrata: Health Sciences, ProQuest - Nursing \& Allied Health Source, Summon (Serials Solutions/ProQuest, TDOne (TDNet), Ulrich's Periodicals Directory/ulrichsweb, WorldCat (OCLC)

Funding: This research received no specific grant from any funding agency in the public, commercial, or not-for-profit sectors.

Conflict of interests:

Corresponding author: Authors have declared that no competing interest exists.

Hamid Arazi (Ph.D.), Department of Exercise Physiology, Faculty of Sport Sciences, University of Guilan, P.O. Box: 41635-1438, Rasht, Iran; tel: +98 911-1399207; e-mail: hamidarazi@yahoo.com.

Open Access License:

is is an open access article distributed under the terms of the Creative Commons Attribution-Non-Commercial-NoDerivatives 4.0 International (https://creativecommons.org/licenses/by-nc-nd/4.0/), which permits use, distribution and reproduction in any medium, provided the original work is properly cited, the use is non-commercial and is otherwise in compliance with the license. 


\section{INTRODUCTION}

Over the past few decades, the aging population has increased with the advent of technology, machine life, improvement in public and individual health and rising life expectancy. In Iran, according to the 2006 census, about $7.2 \%$ of the population $(5,119,000)$ was made up of elderly, which is expected to increase to about $14 \%$ by 2026 . An increase in the aging population is likely to suggest ways to improve the quality of life of the elderly. By increasing age, population and longevity, the risks associated with aging, including diabetes increase [1]. Diabetes is a common metabolic disorder in the world that is associated with increased blood sugar, insufficient secretion or insulin dysfunction, and chronic complications of diabetes are directly related to high blood glucose levels. Approximately, $80 \%$ of people with type 2 diabetes are obese [2]; therefore, obesity can be considered as a primary cause of type 2 diabetes and also insulin resistance. In fact, obesity and decreased physical activity are the most important factors in the development of type 2 diabetes, which, in recent decades, has led to an increase in the number of people with this type of disease. Moreover, fat disorder is one of the common abnormalities in type 2 diabetes, which itself causes and exacerbates the short-term and long-term complications. A significant proportion of diabetic patients are suffering from lipid disorders, which can cause cardiovascular disease [3]. On the other hand, as the age increases, the strength and endurance of the people is reduced; reducing strength and endurance, especially in the lower body, can put an elderly person at risk of falling and causing damage [4]. Therefore, having proper strength and endurance in these patients can be a special point for them. It will facilitate many of their daily activities and help them do all their daily activities [5]. Exercise and proper nutrition have been suggested as the basis for the treatment of diabetes. In addition, several studies have shown clinical benefits of exercise such as improved insulin sensitivity, decreased hemoglobin glycosylated (HBA1c) and increased maximal oxygen consumption (VO2 max) [69]. Despite studies, insulin sensitivity and glycemic and lipid profiles responses to resistance training (RT) are ambiguous [10]; since the use of various drugs is always accompanied by side effects. Today world's health system is working to prevent and treat diseases without using drugs; it seems that participating in a regular exercise program can make a major contribution to reducing diabetes complications and improving the quality of life [11, 12].

The American College of Sports Medicine (ACSM) has recommended that the use of RT can be beneficial as part of a good exercise program for people with type 2 diabetes. Accordingly, RT is defined as a type of exercise that can prevent progressive loss of strength and muscle mass [13]. On the other hand, because of the limited research on the role of RT in elderly people with type 2 diabetes, the Diabetes Association suggests that an RT program for young people with diabetes can be helpful and cannot be judged with certainty for the elderly [14].

However, it has been shown that the major causes of weakness, disability, and loss of autonomy in the elderly are loss of muscle mass and strength progressively with aging, which puts the elderly at risk of functional impairment [15]. Sport interventions that improve musculoskeletal function in the elderly are an effective strategy to increase autonomy in performance and reduce the incidence of many age-related diseases, such as type 2 diabetes [13]. It seems that less attention has been paid to the effects of RT than aerobic exercises on the elderly with type 2 diabetes, and also there is little attention to the longterm effects of RT in this area. 
It has been shown that RT for inactive and elderly people with less muscular strength can be effective in modifying sets in terms of intensity and volume than their active counterparts [16]. Independence in daily activities can be the most important asset of an elderly person, since doing many personal and daily tasks for many elderly people is not possible without the help of other people. Considering the various benefits of physical activity, the present study attempted to investigate the impact of circuit resistance training (CRT) on glucose, insulin resistance and health related physical fitness in elderly men with type 2 diabetes.

\section{MATERIAL AND METHODS}

In this study, a total of 22 patients with type 2 diabetes (age: $60.99 \pm 2.93$ years, weight: $87.07 \pm 5.74 \mathrm{~kg}$, height: $172.74 \pm 5.96 \mathrm{~cm}$ ) participated voluntarily. The participants included inactive and obese men with type 2 diabetes. They were divided randomly into two groups: training and control groups (each group $\mathrm{n}=11$ ) (Figure 1).

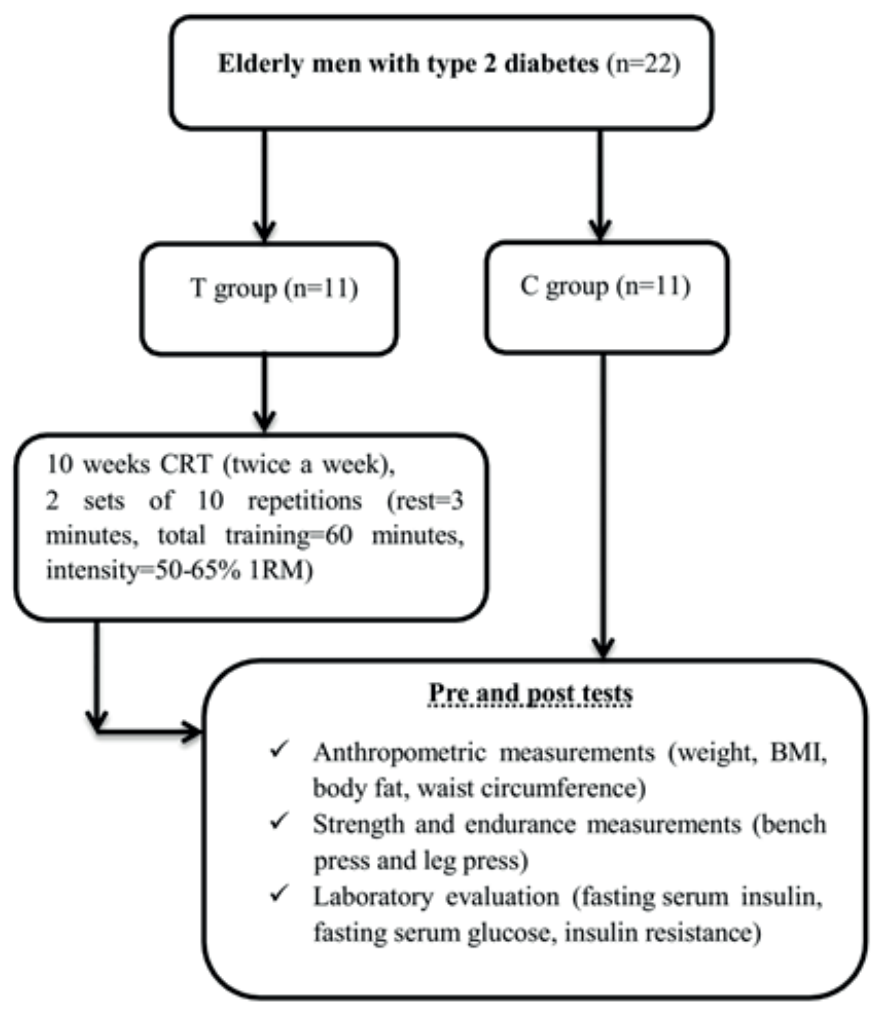

Fig. 1. Experimental design. $\mathrm{T}=$ training, $\mathrm{C}=$ control, $\mathrm{CRT}=$ circuit resistance training, $\mathrm{BMI}=$ body mass index

The subjects were purposefully available according to the criteria for entering this research. At the coordination meeting, the goals and stages of the research were stated and the written consent form was obtained from the subjects. The exclusion criteria included no attendance in exercise session, the occurrence of acute illness during the study, participating in other exercise except the current research protocol. The main criteria for selecting and participating subjects in the present study was: non-development of cardiovascular, skeletal, and metabolic diseases, no diabetic complications (neuropathy, nephropathy, retinopathy), not taking part in regular exercise more than one session in a week during the past 6 months, no smoking, having more than 5 years of diabetes history and not taking more than one type of oral anti-diabetic tablet 24 hours a day (all subjects were taking metformin in the same amount). During the course of this study and training, there was no change in the drugs used for controlling 
blood glucose; also, general and usual drug treatment of type 2 diabetes was performed by an expert physician [17].

The study was approved by the university ethics committee and conducted according to the Declaration of Helsinki.

\section{TRAINING PROTOCOL}

Participants followed a progressive CRT program twice a week for 10 weeks using the following six movements: leg press, chest press, shoulder press, leg curl, front lat pulldown and triceps extension. Training was performed in 2 sets of 10 repetitions with the individual lifting weight; between the sets, participants had to rest for at least 3 minutes and total training duration was 60 minutes. The CRT program included 10 minutes of warm-up, 45 minutes of main exercises, and finally 5 minutes of cool down. In order to make participants familiar with the training program, a detailed introduction at each gym machine was made by qualified fitness trainers, as well as to control the attendance of subjects, 2 training sets had been prepared before the training program began [18]. Each subject warmed up for 10 minutes by doing gentle stretching exercises of the upper and lower body. All RT were recorded and the load incrementally increased (maintained between 50 and $65 \%$ of calculated 1RM) as strength increased to ensure progression (Figure 1).

\section{ANTHROPOMETRIC MEASUREMENTS}

Two days before the start of the training program, anthropometric characteristics and fat percentage (measured with three-point fat percentage measurements and using Jackson and Pollack's equation) were measured. The subjects' weights without shoes were measured using the German Seca digital scale with a precision of $0.1 \mathrm{~kg}$, and height was measured using the German Seca gauge in the standing position near the wall. The body mass index (BMI) was calculated by dividing the individual's weight $(\mathrm{kg})$ by height in square meters. The waist circumference was measured by a strip meter in the narrowest waist. This measure was taken in the standing position, so that the body weight was divided between two legs.

\section{STRENGTH AND ENDURANCE MEASUREMENTS}

To determine 1-RM, each participant initially performed a warm-up set of eight repetitions with a light weight. After the successful completion, a further three to five repetitions at a moderate to heavy weight selected by the instructor were done after a brief rest (1-2 min). The completed repetitions were inserted to Brzycki formula for calculating 1-RM [19]. The 1-RM values on the bench press and leg press exercises were used to document the respective changes in lower and upper body muscle strength. In order to measure muscular endurance, $60 \%$ $1 \mathrm{RM}$ was used. For this purpose, after warm-up of the body, each participant initially performed chest press and leg press with $60 \%$ of the $1 \mathrm{RM}$ to the point of exhaustion, and there was no interruption between performances [19].

\section{LABORATORY EVALUATION}

After 8-12 hour fasting, $10 \mathrm{ml}$ of the blood sample from the left radial artery of the subjects was taken in the pre and post-test (48 hours after the last training session) in the laboratory by lab experts after 10 minutes of rest. Biochemical 
variables were studied. An American kit of diaplus with an ELISA method and sensitivity of $0.5 \mu \mathrm{IU} / \mathrm{ml}$ was used to evaluate serum insulin. Serum glucose was measured directly using commercial kits of Pars Co. of Iran. Insulin resistance was calculated for patients and controls using the homeostasis model assessment (HOMA) [20].

HOMA-IR= fasting serum insulin $(\mu I U / \mathrm{ml}) \times$ fasting serum glucose $(\mathrm{mmol} / \mathrm{l}) / 22.5$

\section{STATISTICAL ANALYSIS}

Descriptive statistics were used to obtain mean and standard deviation. The normal distribution of data was assessed using Shapiro-Wilk test in the dependent variables. T-test was used to examine inter and intra group differences. Statistical operation was performed using SPSS version 22, and a significant level of 5\% was considered.

\section{RESULTS}

The results of t-test showed that the mean post-test of weight, BMI, waist circumference, body fat percentage and metabolic indices in training groups reduced significantly $(\mathrm{P}<0.05)$ (Table 1,2$)$.

Also, the average upper and lower body muscular endurance and strength in the post-test were significantly higher than the pre-test in training group $(\mathrm{P}<0.05)$ (Figure 2).

Table 1. Changes in anthropometric variables within and between groups

\begin{tabular}{|c|c|c|c|c|}
\hline \multirow{2}{*}{ Variable } & \multicolumn{2}{|c|}{ Training } & \multicolumn{2}{|c|}{ Control } \\
\hline & Pre-test & Post-test & Pre-test & Post-test \\
\hline $\begin{array}{l}\text { Weight } \\
(\mathrm{kg})\end{array}$ & $86.73 \pm 5.38$ & $84.28 \pm 5.63^{*} \#$ & $87.42 \pm 6.11$ & $88.32 \pm 4.97$ \\
\hline $\begin{array}{l}\mathrm{BMI} \\
\left(\mathrm{kg} / \mathrm{m}^{2}\right)\end{array}$ & $28.45 \pm 1.92$ & $27.65 \pm 1.40 * \#$ & $29.61 \pm 2.64$ & $29.93 \pm 2.81$ \\
\hline $\begin{array}{l}\text { Body fat } \\
(\%)\end{array}$ & $27.12 \pm 3.18$ & $24.89 \pm 2.48^{*} \#$ & $26.45 \pm 2.3$ & $27.71 \pm 2.52$ \\
\hline $\begin{array}{l}\text { Waist circumference } \\
\text { (cm) }\end{array}$ & $97.25 \pm 6.22$ & $93.20 \pm 3.92 * \#$ & $95.31 \pm 7.81$ & $95.44 \pm 6.49$ \\
\hline
\end{tabular}

*: denotes significant differences between baseline and post-testing values ( $\mathrm{P} \leq 0.05)$; \#: denotes significant differences between the training and control groups at post-testing $(\mathrm{P} \leq 0.05)$. BMI= body mass index.

Table 2. Comparison of metabolic indices within and between groups

\begin{tabular}{lcccc} 
& \multicolumn{2}{c}{ Training } & \multicolumn{2}{c}{ Control } \\
\cline { 2 - 5 } Variable & Pre-test & Post-test & Pre-test & Post-test \\
\cline { 2 - 5 } & $176.31 \pm 46.63$ & $152.41 \pm 37.59^{*} \#$ & $168.12 \pm 35.08$ & $174.66 \pm 32.67$ \\
$\begin{array}{l}\text { Serum glucose } \\
(\mathrm{mg} / \mathrm{dl})\end{array}$ & $12.39 \pm 3.22$ & $10.62 \pm 2.56^{*} \#$ & $11.82 \pm 2.67$ & $11.91 \pm 2.38$ \\
$\begin{array}{l}\text { Serum insulin } \\
(\mu \mathrm{lU} / \mathrm{ml})\end{array}$ & $5.38 \pm 3.19$ & $3.98 \pm 2.91^{*} \#$ & $4.90 \pm 3.01$ & $5.12 \pm 2.49$ \\
Insulin resistance & & & & \\
\hline
\end{tabular}

*: denotes significant differences between baseline and post-test values ( $\mathrm{P} \leq 0.05)$; \#: denotes significant differences between the training and control groups at post-test $(\mathrm{P} \leq 0.05)$. 
a
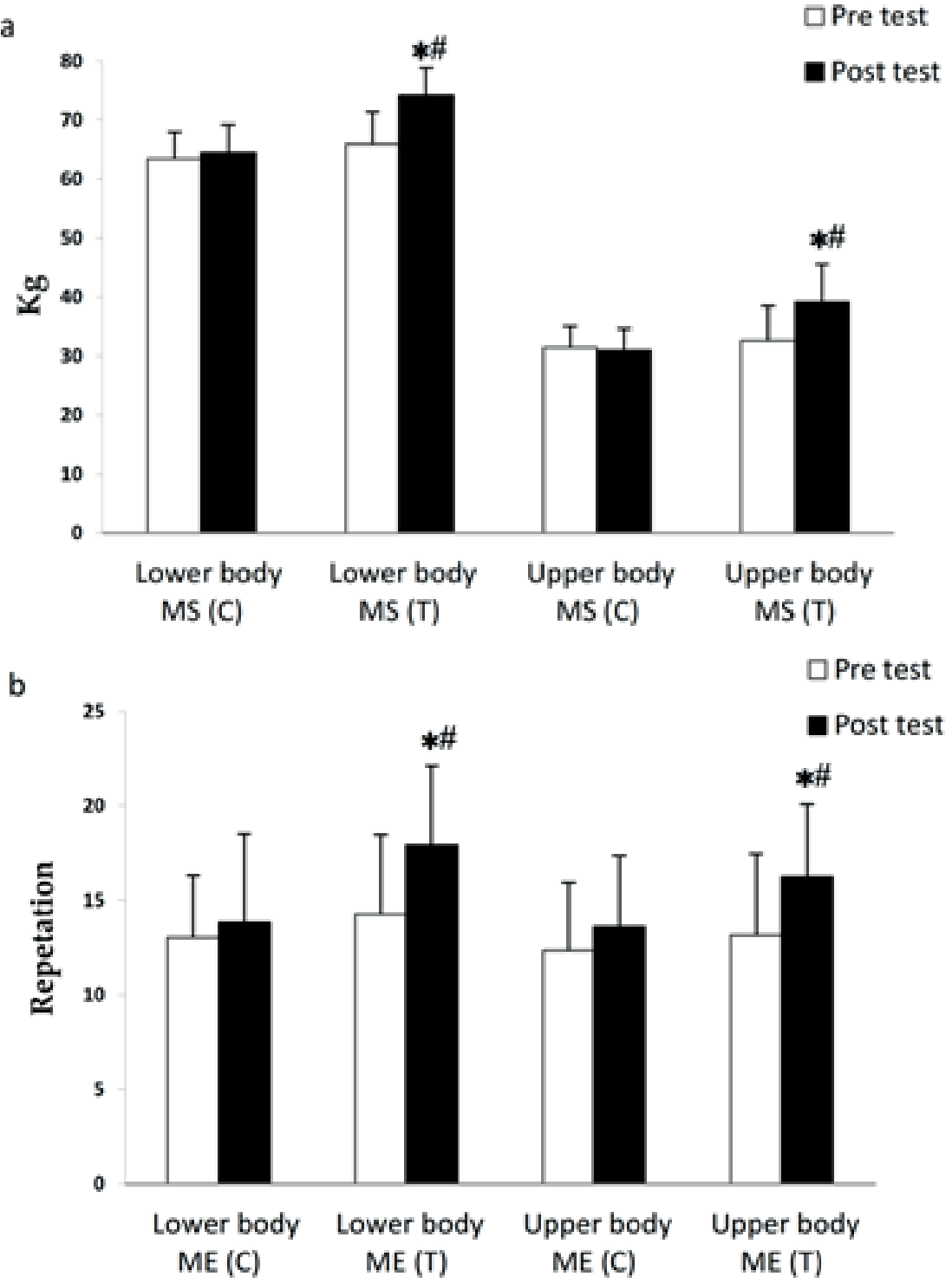

Fig. 2. Changes in strength (a) and endurance (b) within and between groups.

*: denotes significant differences between baseline and post-test values $(\mathrm{P} \leq 0.05)$; \#: denotes significant differences between the $\mathrm{T}$ and $\mathrm{C}$ groups at post-test $(\mathrm{P} \leq 0.05)$. MS $=$ muscle strength, $\mathrm{ME}=$ muscle endurance, $\mathrm{T}=$ training, $\mathrm{C}=\mathrm{control}$.

The results of the independent t-test indicated that CRT had a statistically significant effect on weight, BMI, body fat and waist circumference compared with control groups $(\mathrm{P}<0.05)$ (Table 1).

After the intervention, the increase in 1-RM leg press (lower body) and bench press (upper body) was significantly greater in the training group (pre: 65.97 \pm 5.86 , post: $74.13 \pm 6.45$; pre: $32.62 \pm 5.43$, post: $39.15 \pm 4.70$; respectively) than in the control one (pre: $63.39 \pm 7.10$, post: $64.52 \pm 6.72$; pre: $31.41 \pm 4.56$, post: $30.89 \pm 4.73$; respectively) $(\mathrm{P}<0.05$, Figure $2 \mathrm{a})$. Also, the change upper and lower body muscular endurance was significantly higher in the training group (pre: $13.18 \pm 4.30$, post: $16.25 \pm 3.82$; pre: $14.26 \pm 4.19$, post: 17.92 \pm 4.20 ; respectively) than in the control one (pre: $12.35 \pm 3.60$, post: 13.61 \pm 3.76 ; pre: $13.06 \pm 3.27$, post: $13.83 \pm 4.66$; respectively) $(P<0.05$, Figure $2 b)$. Also, the training group had lower fasting serum glucose, fasting insulin and insulin resistance when compared with the control group $(\mathrm{P}<0.05$, Table 2$)$. 


\section{DISCUSSION}

The purpose of this study was to investigate the impact of CRT on serum glucose, insulin resistance and health related physical fitness in elderly men with type 2 diabetes. The results showed that the pre and post-test variations in training group were significant; in addition, changes in anthropometric variables, metabolic indices, strength and endurance in the training group were significant compared to the control group.

In the present study, upper and lower body strength and endurance in posttest training group increased significantly. The results of this study were consistent with the results of Lai et al. [21]. In their review article, they stated that RT improved muscle strength compared to other exercises. On the other hand, increasing the length of the training period has more positive effects on muscle mass. Development of strength and muscular endurance after RT involves coordinated performance of various processes. In fact, the ability to generate more strength is related to both the nervous and the muscular system. Adaptations created as a result of RT include: nervous adaptations such as increasing the number of motion units, using motor units in the muscles, stimulating more motor units with greater frequency, increasing the skill and coordination of the musculoskeletal system in the movements, muscular adaptations, such as increased cross-sectional muscle and changes in muscle structure and metabolic adaptations [22].

Increased strength is attributed to the gradual increase in myofibrils size [22, 23]. As the age increases, the number of falls increases, which is a major cause of the weakness of the lower body in the elderly [24]. Actually, the most important issue in improving the health of the elderly is to maintain their independence in daily activities, their daily functioning, and active living [25]. In fact, upper body muscles are used in the daily activities, so having proper endurance and strength in these muscles can be very valuable. These observations indicate that performing two sessions of CRT for 60 minutes a week is very reassuring for type 2 diabetes management, and it can be used as an adjunct therapy to help manage this type of disease in older men. Several mechanisms have been proposed to increase insulin sensitivity after exercise [26]. It has also been argued that the change in the production of adipokines with exercise may play an important role in cardiovascular disease due to obesity and insulin resistance [26]. Exercise may also affect the metabolism of adipocytes and, as a result, alter the serum level of resistin and adiponectin and thereby affect insulin sensitivity [27]. Physical activity also increases available glucose by insulin levels throughout the body in type 2 diabetic obese individuals. These changes are related to functional changes in insulin signals and are related to the increased content of the membrane glucose transporter type 4 (GLUT4). Exercise, apart from boosting insulin function by increasing GLUT-4 receptors, increases glucose uptake $[27,28]$. The results of this study indicated that there was a significant change in fasting serum glucose and insulin resistance between two groups. In line with the results of this study, Russell et al. [29] reported improvement in blood glucose and insulin resistance after performing RT among patients. Kirwan et al. [30] reported a decrease in insulin resistance and increased glucose elimination during a 7-day heavy exercise, with no changes in BMI and weight. Misra et al. [31] reported a significant decrease in levels of body fat, insulin, and HOMA-IR during 12 weeks of RT. Dunstan et al. [7] also argued that progressive RT along with nutritional control has improved blood glucose level and also increased strength in these patients. 
In type 2 diabetes, increased physical activity reduces fasting serum glucose and insulin levels, which indicates increased insulin sensitivity [32]. The results of this study regarding serum insulin levels showed that CRT resulted in significant decrease in this index. These results were consistent with the findings of other researchers [33, 34]. Suh et al. [34] evaluated the effect of 12 weeks of aerobic and RT with controlled diet on overweight men. It was concluded that the insulin levels of both groups (aerobic and RT) were significantly lower than those in the diet group.

Skeletal tissue contributes to insulin resistance, and exercise can improve insulin sensitivity of the skeletal muscle and the entire body by improving glucose metabolism. Incremental setting of AMP-activated protein kinase (AMPK) is a mechanism that improves insulin sensitivity due to exercise [35]. As a result of exercise, the expression of the GLUT4 and its transfer to the plasma membrane in skeletal muscle increases with AMPK and finally the entry of glucose into muscle cells and its use is facilitated. This process is associated with increased activity of glycogen synthase and hexokinase, reducing the releasing and enhancing the cleansing of free fatty acids, increased glucose release from blood to the muscle due to increased muscle capillaries and changes in muscle composition which leads to more glucose consumption and a decrease in blood glucose levels [33].

Patients with type 2 diabetes are frequently obese and have abnormal amounts of intra-abdominal and subcutaneous fat. The accumulation of intra-abdominal fat especially increases the risk of developing metabolic and cardiovascular diseases [36]. Yang et al. [37] indicated that aerobic exercise may reduce BMI more and improve physical fitness $\left(\mathrm{VO}_{2} \max\right.$, maximum heart rate) better than RT. They believe that the biological mechanism underlying this difference is unclear. However, RT mainly increases the size and strength of muscles, while aerobic exercises burn the stored fat for energy. In this study, the researchers assessed weight, BMI and waist circumference. We also observed a significant reduction in the waist circumference, body weight and BMI over time in the training group, which is well in keeping even with programs that ran for longer periods. In fact, we can say that RT has a unique effect on patients with type 2 diabetes by slowing sarcopenia and thus slowing gain in body fat, particularly visceral fat. RT is metabolically less demanding than aerobic training and also, RT would be most effective in slowing the development of sarcopenic obesity [38].

\section{CONCLUSIONS}

Based on the results of this study, it seems that:

- Regular CRT with a frequency of twice a week could be beneficially performed by elderly men with type 2 diabetes.

- CRT can be a logical exercise form in a weight management program, particularly for muscular strength and endurance developments which are required in all daily activities of the elderly.

- CRT for 10 weeks leads to significant improvement in health related factors such as insulin resistance, fasting serum glucose and BMI in elderly men with type 2 diabetes. 


\section{ACKNOWLEDGEMENTS}

The authors wish to thank all participants who took part in the study.

\section{REFERENCES}

[1] Darbani M, Torkaman G, Movassaghe S, Bayat N. Comparison of the hip, ankle and back extensor muscle strength and its correlation with functional balance in healthy and osteoporotic postmenopausal women. J Modern Rehabil. 2015;9(1):40-52.

[2] Gomez-Perez FJ, Aguilar-Salinas CA, Almeda-Valdes P, Cuevas-Ramos D, Garber IL, Rull JA. HbA1c for the diagnosis of diabetes mellitus in a developing country. A position article. Arch Med Res. 2010;41(4):302-8. https://doi.org/10.1016/j.arcmed.2010.05.007

[3] Larejani B, Zahedi F. Epidemiology of diabetes mellitus in Iran. Iran J Diabet Metb. 2001;1(1):1-8.

[4] Peterson MJ, Giuliani C, Morey MC, et al. Physical activity as a preventative factor for frailty: the health, aging, and body composition study. J Gerontol: Series A. 2009;64(1):61-8. https://doi. org/10.1093/gerona/gln001

[5] Sterrett JJ, Bragg S, Weart CW. Type 2 diabetes medication review. Am J Med Sci. 2016;351(4):342 55. https://doi.org/10.1016/j.amjms.2016.01.019

[6] Magkos F, Yannakoulia M, Chan JL, Mantzoros CS. Management of the metabolic syndrome and type 2 diabetes through lifestyle modification. Ann Rev Nutrition. 2009;29:223-56. https://doi.org/10.1146/ annurev-nutr-080508-141200

[7] Dunstan DW, Daly RM, Owen N, et al. High-intensity resistance training improves glycemic control in older patients with type 2 diabetes. Diabetes Care. 2002;25(10):1729-36. https://doi.org/10.2337/ diacare.25.10.1729

[8] Praet SF, van Loon LJ. Exercise therapy in type 2 diabetes. Acta Diabetologica. 2009;46(4):263-78 https://doi.org/10.1007/s00592-009-0129-0

[9] Szalewska D, Tomaszewski J, Kusiak-Kaczmarek M, et al. Influence of a hybrid form of cardiac rehabilitation on exercise tolerance in coronary artery disease patients with and without diabetes. Kardiologia Polska (Polish Heart Journal). 2015;73(9):753-60. https://doi.org/10.5603/KP.a2015.0088

[10] Hawley JA, Lessard S. Exercise training-induced improvements in insulin action. Acta Physiologica. 2008;192(1):127-35. https://doi.org/10.1111/j.1748-1716.2007.01783.x

[11] Kelley GA, Kelley KS. Impact of progressive resistance training on lipids and lipoproteins in adults: A meta-analysis of randomized controlled trials. Prevent Med. 2009;48(1):9-19. https://doi org/10.1016/j.ypmed.2008.10.010

[12] Cauza E, Hanusch-Enserer U, Strasser B, et al. The relative benefits of endurance and strength training on the metabolic factors and muscle function of people with type 2 diabetes mellitus. Arch Phys Med Rehabil. 2005;86(8):1527-33. https://doi.org/10.1016/j.apmr.2005.01.007

[13] Thompson WR, Gordon NF, Pescatello LS. ACSM's guidelines for exercise testing and prescription. Lippincott Williams \& Wilkins; 2010.

[14] Thomas D, Elliott EJ, Naughton GA. Exercise for type 2 diabetes mellitus. Cochrane Database of Systematic Reviews. 2006 (3). https://doi.org/10.1002/14651858.CD002968.pub2

[15] Castaneda C, Layne JE, Munoz-Orians L, et al. A randomized controlled trial of resistance exercise training to improve glycemic control in older adults with type 2 diabetes. Diabetes Care. 2002;25(12):2335-41. https://doi.org/10.2337/diacare.25.12.2335

[16] Brooks NL, Moore KS, Clark RD, Perfetti MT, Trent CM, Combs TP. Do low levels of circulating adiponectin represent a biomarker or just another risk factor for the metabolic syndrome? Diabet Obesity Metab. 2007;9(3):246-58. https://doi.org/10.1111/j.1463-1326.2006.00596.x

[17] Yousefipoor P, Tadibi V, Behpoor N, Parnow A, Delbari M, Rashidi S. Effects of aerobic exercise on glucose control and cardiovascular risk factor in type 2 diabetes patients. Med J Mashhad Uni Med Sci. 2015;57(9):976-84

[18] Chodzko-Zajko WJ, Proctor DN, Singh MAF, Minson CT, Nigg CR, Salem GJ, et al. Exercise and physical activity for older adults. Medicine \& science in sports \& exercise. 2009;41(7):1510-30. https://doi. org/10.1249/MSS.0b013e3181a0c95c

[19] Tan B. Manipulating resistance training program variables to optimize maximum strength in men: A review. J Strength Condition Res. 1999;13(3):289-304. https://doi.org/10.1519/00124278199908000-00019

[20] Matthews D, Hosker J, Rudenski A, Naylor B, Treacher D, Turner R. Homeostasis model assessment: Insulin resistance and $\beta$-cell function from fasting plasma glucose and insulin concentrations in man Diabetologia. 1985;28(7):412-9. https://doi.org/10.1007/BF00280883

[21] Lai CC, Tu YK, Wang TG, Huang YT, Chien KL. Effects of resistance training, endurance training and whole-body vibration on lean body mass, muscle strength and physical performance in older people: A systematic review and network meta-analysis. Age and Ageing. 2018;47(3):367-73. https:// doi.org/10.1093/ageing/afy009

[22] Ratamess NA, Alvar BA, Evetoch TE, et al. Progression models in resistance training for healthy adults. Med Sci Sport Exerc. 2009;41(3):687-708. https://doi.org/10.1249/MSS.0b013e3181915670

[23] Bird SP, Tarpenning KM, Marino FE. Designing resistance training programmes to enhance muscular fitness. Sport Med. 2005;35(10):841-51. https://doi.org/10.2165/00007256-200535100-00002 
[24] Wood L, Peat G, Thomas E, Hay EM, Sim J. Associations between physical examination and self-reported physical function in older community-dwelling adults with knee pain. Phys Ther. 2008;88(1):33-42. https://doi.org/10.2522/ptj.20060372

[25] Payne VG, Isaacs LD. Human motor development: A lifespan approach. Routledge; 2017. https://doi. org/10.4324/9781315213040

[26] Henriksen EJ. Invited review: Effects of acute exercise and exercise training on insulin resistance. Jf Appl Physiol. 2002;93(2):788-96. https://doi.org/10.1152/japplphysiol.01219.2001

[27] Feinman RD, Pogozelski WK, Astrup A, et al. Dietary carbohydrate restriction as the first approach in diabetes management: critical review and evidence base. Nutrition. 2015;31(1):1-13. https://doi. org/10.1016/j.nut.2014.06.011

[28] Vu V, Riddell MC, Sweeney G. Circulating adiponectin and adiponectin receptor expression in skeletal muscle: Effects of exercise. Diabet Metab Res Rev. 2007;23(8):600-11. https://doi.org/10.1002/ dmrr.778

[29] Russell RD, Hu D, Greenaway T, et al. Skeletal muscle microvascular-linked improvements in glycemic control from resistance training in individuals with type 2 diabetes. Diabetes Care. 2017;40(9):125663. https://doi.org/10.2337/dc16-2750

[30] Kirwan JP, Solomon TP, Wojta DM, Staten MA, Holloszy JO. Effects of 7 days of exercise training on insulin sensitivity and responsiveness in type 2 diabetes mellitus. Am J Physiol-Endocrinol Metab. 2009;297(1):E151-E6. https://doi.org/10.1152/ajpendo.00210.2009

[31] Misra A, Alappan NK, Vikram NK, Goel K, Gupta N, Mittal K, et al. Effect of supervised progressive resistance-exercise training protocol on insulin sensitivity, glycemia, lipids, and body composition in Asian Indians with type 2 diabetes. Diabetes Care. 2008;31(7):1282-7. https://doi.org/10.2337/ dc07-2316

[32] Marwick TH, Hordern MD, Miller T, et al. Exercise training for type 2 diabetes mellitus: Impact on cardiovascular risk: A scientific statement from the American Heart Association. Circulation. 2009;119(25):3244-62. https://doi.org/10.1161/CIRCULATIONAHA.109.192521

[33] Durante PE, Mustard KJ, Park S-H, Winder WW, Hardie DG. Effects of endurance training on activity and expression of AMP-activated protein kinase isoforms in rat muscles. Am J Physiol-Endocrinol and Metab. 2002;283(1):E178-E86. https://doi.org/10.1152/ajpendo.00404.2001

[34] Suh S, Jeong I-K, Kim MY, et al. Effects of resistance training and aerobic exercise on insulin sensitivity in overweight Korean adolescents: a controlled randomized trial. Diabet Metab J. 2011;35(4):418-26. https://doi.org/10.4093/dmj.2011.35.4.418

[35] Kadoglou NP, Vrabas IS, Kapelouzou A, et al. The impact of aerobic exercise training on novel adipokines, apelin and ghrelin, in patients with type 2 diabetes. Medical science monitor. Int Med J Experim Clin Res. 2012;18(5):CR290. https://doi.org/10.12659/MSM.882734

[36] Egger A, Niederseer D, Diem G, et al. Different types of resistance training in type 2 diabetes mellitus: effects on glycaemic control, muscle mass and strength. Eur J Prevent Cardiol. 2013;20(6):1051-60. https://doi.org/10.1177/2047487312450132

[37] Yang Z, Scott CA, Mao C, Tang J, Farmer AJ. Resistance exercise versus aerobic exercise for type 2 diabetes: a systematic review and meta-analysis. Sport Med. 2014;44(4):487-99. https://doi. org/10.1007/s40279-013-0128-8

[38] Hills AP, Shultz S, Soares MJ, et al. Resistance training for obese, type 2 diabetic adults: A review of the evidence. Obesity Rev. 2010;11(10):740-9. https://doi.org/10.1111/j.1467-789X.2009.00692.x 